\title{
Post-retirement employment
}

Grant Schellenberg, Martin Turcotte and Bali Ram

ndividuals enter retirement in many different ways. Some retire from a long-term job, making a clean transition from work to leisure. Others take less direct routes, perhaps paring back their work hours, experiencing a spell of unemployment, or changing jobs or even careers late in their working life. There are also some who retire and later return to the workforce. This situation is becoming more common as retirees increasingly find themselves in good health and with the education and skills needed to compete in the job market. Indeed, demand for their skills may increase in the coming years as baby boomers retire and the face of the labour force changes. Using the 2002 General Social Survey, this article examines the latter group: individuals who return to paid employment after an initial retirement (see Data source and definitions).

Retired individuals were asked if they had done any paid work, at any time, at any job or business after their first retirement. Just over one-fifth $(22 \%)$ of recent retirees said they had done so. ${ }^{1}$ Another $4 \%$ said they had looked for a job, but had not been able to find one. ${ }^{2}$

\section{Characteristics associated with post-retirement employment}

Various characteristics influenced the likelihood of returning to work after an initial retirement (Table 1). Men were slightly more likely than women (predicted probabilities of $23 \%$ and $15 \%$ respectively). Health was also a key consideration. Individuals in fair or poor health were far less likely to return to work than those whose health was excellent (predicted probabilities of $12 \%$ and $24 \%$ respectively).

Grant Schellenberg and Martin Turcotte are with the Social and Aboriginal Statistics Division. Grant Schellenberg can be reached at (613) 951-9580. Martin Turcotte at (613) 951 2290. Bali Ram is with Demography Division; he can be reached at 613) 951-2347. All three authors can be reached at perspectives@statcan.ca.

\section{Data source and definitions}

The 2002 General Social Survey targeted all persons 45 and over residing in the 10 provinces, excluding full-time residents of institutions.

The survey used a subjective definition of retirement involving several steps. First, respondents who said their main activity during the past 12 months was 'retired' were identified as retirees. Individuals who did not indicate retirement as their main activity were asked if they had ever retired, and those who said yes were also identified as retirees. Those who still responded no were asked a follow-up question that probed the issue in considerable detail, and if they were able to answer positively to any part of this question, they were also deemed to be retirees. Respondents who had never worked, had left the labour force before age 30 , or did not answer the questions on retirement were excluded from the study.

Recent retirees are individuals who first retired during the years 1992 to 2002 inclusive and were aged 50 or older at the time.

Post-retirement employment was more common among those retiring from certain occupations and industries. Individuals from professional occupations were most likely to return to work (predicted probability of $27 \%$ ), followed by managers and technicians $(21 \%)$. These figures may reflect greater and more attractive employment opportunities available to these individuals-jobs offering good pay, interesting work and few physical demands.

From an industry standpoint, retirees from information, culture and recreation as well as construction were most likely to return to the workforce. Employment in construction is often project-oriented, so retirees here have more opportunity to find employment in temporary, project-specific jobs. Furthermore, plumbers, carpenters, electricians and others in skilled trades may be well-positioned to supplement retirement income through self-employment. In fact, $31 \%$ of retirees from the construction industry were selfemployed prior to their first retirement, compared with $17 \%$ of all retirees. 
Table 1 Predicted probability of recent retirees having returned to paid employment

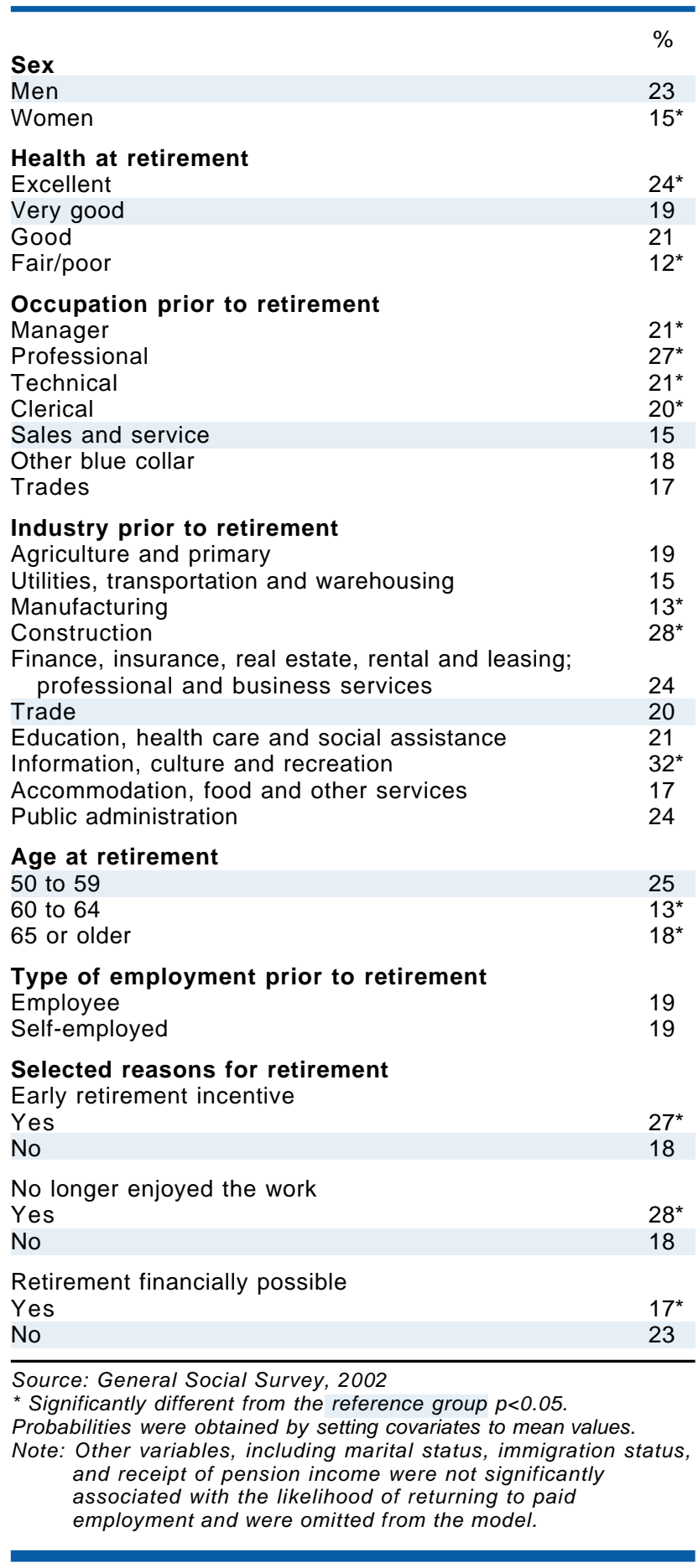

The likelihood of returning to paid employment was also associated with age. Individuals who first retired before age 60 were more likely to return to work than those who retired later. Perhaps those under 60 had concerns about their financial preparations or were not yet psychologically ready for retirement.

Finally, the likelihood of post-retirement employment was linked to specific retirement reasons-most notably, receipt of an early retirement incentive and no longer enjoying one's work. In the latter case, postretirement employment may reflect the efforts of some individuals to start a new career or to find employment in a more satisfying work environment. In addition, individuals who retired for reasons other than financial were more likely to return to work, likely in an effort to improve their financial situation.

\section{Reasons for post-retirement employment}

Retirees returning to paid employment were asked why they did so. Although financial considerations was mentioned most often, it was cited by considerably less than half $(38 \%)$ (Chart). This suggests that nonfinancial reasons were important as well. Indeed, $22 \%$ of retirees returned to employment because they did not like retirement, $19 \%$ mentioned the intrinsic

\section{Chart Financial issues by far the most common reason for returning to work}

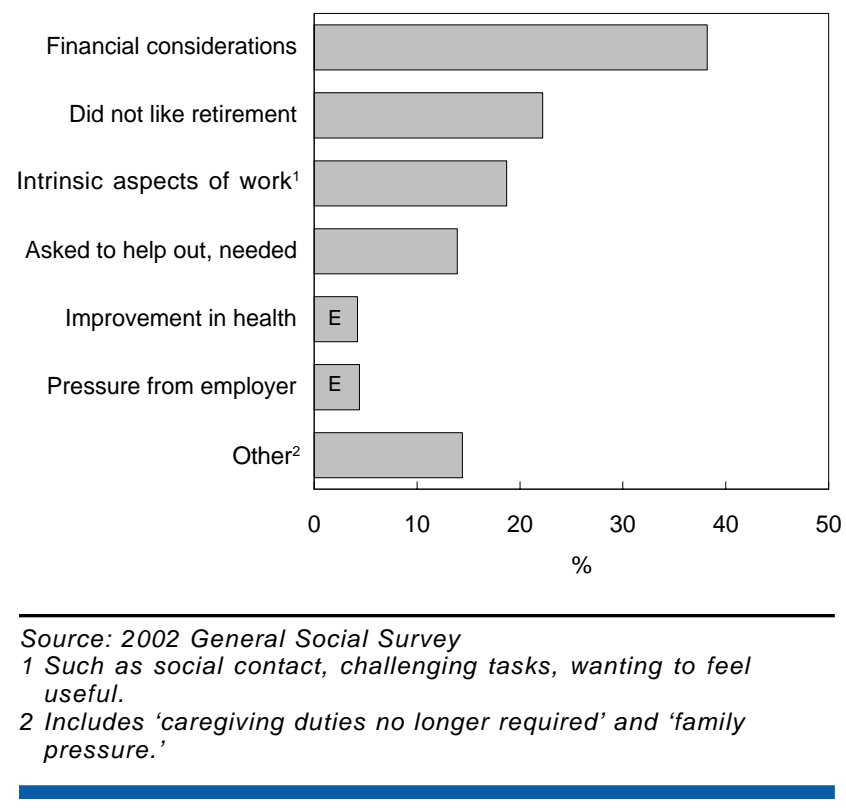


rewards offered by work (challenging tasks, social contacts, sense of purpose), and $14 \%$ felt they were needed or wanted to help out. Overall, $55 \%$ cited at least one of these three non-financial reasons. Other considerations, such as pressure from family members, improved health, or no longer having to provide caregiving, were cited by less than $5 \%$.

The likelihood of returning to work for financial reasons did not vary by sex or educational attainment (Table 2). Voluntary and involuntary retirees differed noticeably on this point, however with financial considerations being cited more often by those who left involuntarily (54\% versus $33 \%$ ). Similarly, individuals who retired because of health problems, downsizing or unemployment were more likely to return to work for financial reasons.

Among the $4 \%$ of recent retirees who looked for a job but were unsuccessful in finding one, $40 \%$ cited wanting to return to work for financial reasons, 39\% non-financial reasons, and $22 \%$ both.

\section{Table 2 Reasons why recent retirees returned} to work after first retirement ${ }^{1}$

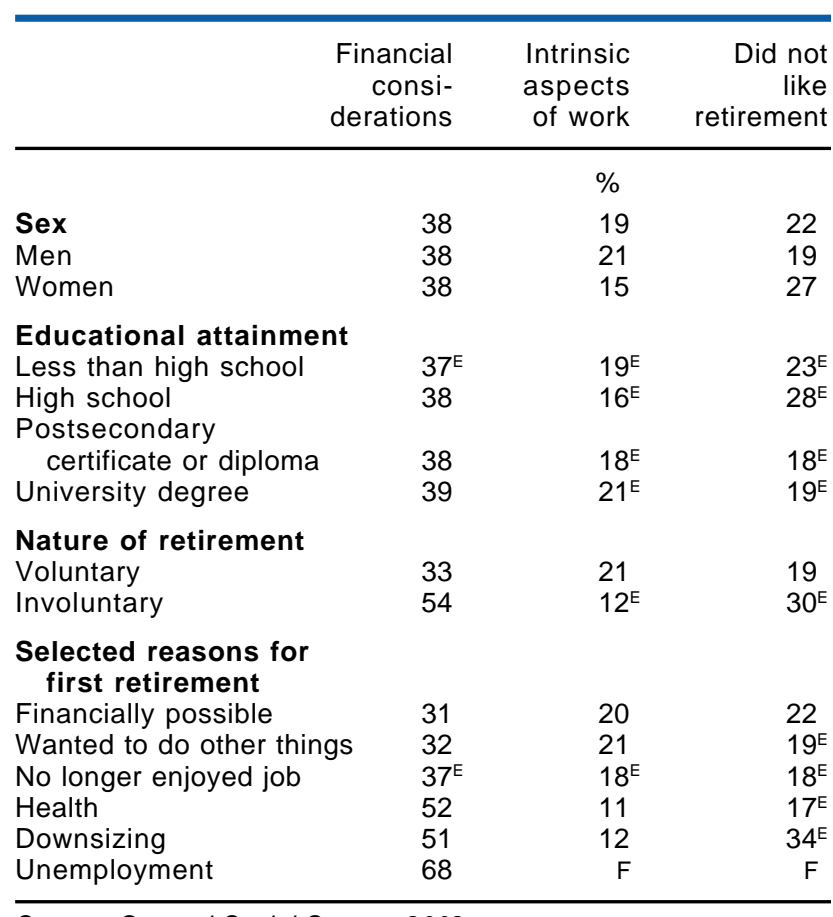

Source: General Social Survey, 2002

1 Top three reasons.

\section{Hours worked after retirement}

Many retirees who returned to paid employment did so on a part-time basis (less than 30 hours per week)$37 \%$ of men and $58 \%$ of women (Table 3 ). Individuals who initially retired at 60 or later were more likely to work part time than those who retired before 60 .

Work hour preferences are most divergent among men and women with higher levels of education. The difference in the incidence of part-time employment between men and women with high school or less (10 to 12 percentage points) was far smaller than for those with a postsecondary certificate or diploma (26 percentage points) or a university degree (33 points).

Finally, for retirees who were employed just prior to their first retirement, post-retirement employment often involved a reduction in the number of hours worked. Of the men returning to paid employment, virtually all had worked full time prior to their first retirement. However, over one-third of them moved to a part-time schedule when they took post-retirement employment. Similarly, among women, of the $86 \%$ who were employed full time prior to their first retirement, over half $(55 \%)$ moved to a part-time schedule when they returned to work. This suggests that many workers considering retirement might be willing to continue working if switching to part-time were an option. ${ }^{3}$

\section{Table 3 Recent retirees who returned to part-time paid employment}

\begin{tabular}{|c|c|c|c|}
\hline & $\begin{array}{l}\text { Both } \\
\text { sexes }\end{array}$ & Men & Women \\
\hline & & $\%$ & \\
\hline Total & 45 & 37 & 58 \\
\hline $\begin{array}{l}\text { Age at first retirement } \\
50 \text { to } 59 \\
60 \text { to } 64 \\
65 \text { or older }\end{array}$ & $\begin{array}{l}41 \\
48^{\mathrm{E}} \\
55^{\mathrm{E}}\end{array}$ & $\begin{array}{l}31 \\
46^{\mathrm{E}} \\
49^{\mathrm{E}}\end{array}$ & $\begin{array}{l}59 \\
52^{\mathrm{E}} \\
67^{\mathrm{E}}\end{array}$ \\
\hline \multicolumn{4}{|l|}{ Education } \\
\hline Less than high school & $40^{\mathrm{E}}$ & $36^{\mathrm{E}}$ & $48^{\mathrm{E}}$ \\
\hline $\begin{array}{l}\text { High school } \\
\text { Postsecondary }\end{array}$ & 51 & $47^{\mathrm{E}}$ & $57^{\mathrm{E}}$ \\
\hline certificate or diploma & 49 & $36^{\mathrm{E}}$ & $62^{\mathrm{E}}$ \\
\hline University degree & 38 & $27^{\mathrm{E}}$ & $60^{\mathrm{E}}$ \\
\hline
\end{tabular}

Source: General Social Survey, 2002 


\section{Conclusion}

In general, post-retirement employment has been most prevalent among individuals who initially retired in their 50s and were well positioned to re-enter the workforce. They were in good health, had postsecondary educational credentials, and valuable skills and experience-often gained from prior employment in professional and managerial occupations. ${ }^{4}$ While financial considerations were the motivation for some, the intrinsic aspects of work were important for others.

Looking ahead, a number of factors may influence the prevalence of post-retirement employment in Canada-educational attainment for one. The proportion of individuals aged 55 to 64 with a postsecondary educational credential increased from $25 \%$ to $48 \%$ between 1990 and 2004, while those with less than high school declined from $54 \%$ to $27 \%$ (Statistics Canada 2005). ${ }^{5}$ Hence, the upcoming cohort of retirees will be well educated and equipped to re-enter the workforce after retirement if they so choose.

Also, individuals in their retirement years will be in better health than their predecessors. A recent Statistics Canada study compared the health of persons aged 50 to 67 (as well as other age groups) in 1978-79 and 1996-97 and concluded that "Lower mortality rates overall, and for cardiovascular disease in particular, as well as lower odds of heart disease, high blood pressure, arthritis and activity limitation suggest that recent cohorts are healthier than the cohorts who preceded them." (Chen and Millar 2000, 19). The implication is that health considerations will be an obstacle for fewer retirees wanting to re-enter the workforce.

Finally, unlike retirees in the 1990s, those in the years ahead will face a labour market where demand for their labour is high. With greater employment prospects available, older workers who might otherwise have opted to retire from long-held jobs may instead capitalize on the opportunity for a career change.

On the other hand, in coming years, more new retirees will be women - a result of their increased participation in the labour market over the last few decades. Among individuals aged 45 to 54 working full year, full time in 2000, 46\% were women compared with only $29 \%$ in 1980 . If women now approaching retirement behave similarly to those who retired between 1992 and 2002 - that is, their incidence of post-retirement employment remains lower than men's - then the proportion of new retirees returning to the workforce may not grow as quickly.

\section{Notes}

1 Retired respondents were asked in what month and year they first retired and, if they subsequently took a paid job, in what month and year they last retired. In some cases, the month and year of the first and last retirement were the same, raising doubt as to whether significant post-retirement employment was undertaken. If these respondents are excluded, the incidence of post-retirement employment drops from $22 \%$ to $20 \%$. In this study, the analysis of postretirement employment is based on all respondents who said they took paid employment after their initial retirement (that is, the $22 \%$ figure).

2 The majority of these job seekers (63\%) cited unemployment or downsizing as the reason for their initial retirement. Information on individuals who looked for a job but did not find one is not included here, since the small number of respondents limits the extent to which reliable comparisons across demographic and labour market characteristics can be made.

3 Aside from hours of work, the 2002 General Social Survey did not collect information on the kind of employment undertaken by retirees who re-entered the workforce. Longitudinal surveys, such as the Survey of Labour and Income Dynamics, are better equipped to explore changes over time.

4 More specifically, of all recent retirees who returned to the workforce, $64 \%$ initially retired before age $60,63 \%$ were in very good or excellent health, $54 \%$ had a postsecondary educational credential, and $39 \%$ had been employed previously in a managerial or professional occupation.

5 The absolute number of older workers with less than high school education also declined, from 1.3 million in 1990 to 909,000 in 2004 .

\section{References}

Chen, Jiajian and Wayne J. Millar. 2000. "Are recent cohorts healthier than their predecessors?" Health Reports 11, no. 4 (Spring): 9-24.

Statistics Canada. 2005. Labour force historical review. CD-ROM. 